\title{
Terbiyum (Tb) Katkılı Arayüzeyin Al/p-Si Schottky Diyotların Elektrik Karakteristikleri Üzerine Etkisi
}

\author{
Ömer Sevgili \\ Bingol Üniverstesi, Sağllk Hizmetleri Meslek Yüksekokulu, Bingol, Türkiye \\ omersevgili06@gmail.com (D) \\ Makale gönderme tarihi: 05.01.2021, Makale kabul tarihi: 21.03.2021
}

\begin{abstract}
Öz
Bu çalışmada Terbiyum katkılı Seryum Magnezyum Alüminat, metal ve yariiletken kristal arasına bir tabaka olarak döner-kaplama yöntemi kullanılarak oluşturuldu. Arayüzeye sahip Schottky Diyotun ve arayüzeysiz Schottky Diyotun elektiksel özellikleri $( \pm 2 \mathrm{~V})$ aralığında Akım-Gerilim ölçümleri kullanılarak birbirleriyle karşılaştırıldı. Bu diyotların idealite faktörü, doyma akımı, sıfır beslem engel yüksekliği ve seri direnç değerleri hem Termiyonik Emisyon metodu hem de Norde Fonksiyonu kullanılarak hesaplandı. Deneysel sonuçlar Terbiyum katkılı Seryum Magnezyum Alüminat arayüzeyine sahip diyotun arayüzeysiz diyot ile karşılaştırıldığında seri direnç, idealite faktörü ve arayüzey durumları bakımından iyileştirdiğini gösterdi. Ayrıca her iki diyot içinde doğru beslemdeki (V>0) akım iletim mekanizması incelendi ve bu bölgede iki diyotunda eğimleri birbirlerinden farklı üç lineer bölgeye sahip olduğu görüldü. Dahası arayüzey durumlarının enerji dağılımı da incelendi ve kullanılan arayüzey tabakasının varlığından dolayı arayüzeysiz Schottky Diyotun arayüzey durumlarına göre azalmasını sağladı̆̆ı görüldü.
\end{abstract}

Anahtar kelimeler: Ara yüzey tabakasının etkisi, elektrik karakteristik, terbiyum, seryum magnezyum alüminat

\section{The effect of Terbium (Tb) doped interface on the electrical characteristics of Al /p-Si Schotkky Diodes}

\begin{abstract}
In this study, Terbium doped Cerium Magnesium Aluminate was fabricated using the spin-coating method as a layer between the semiconductor and metal. The electrical properties of the Schottky Diodes with and without interfacial layer were compared using Current-Voltage measurements in the range of $( \pm 2 \mathrm{~V})$. The ideality factor, saturation current, zero bias barrier height and series resistance values of these diodes were calculated using both the Thermionic Emission method and the Norde Function. The experimental results showed that diode with the Terbiumdoped Cerium Magnesium Aluminate interface improved compared to the diode without the interface in terms of series resistance, ideality factor and interface states. In addition, the current transmission mechanism at forward bias (V>0) was examined in both diodes and it was seen that both diodes had three linear regions with different slope. Moreover, the energy distribution of the interface states was also examined and it was seen that Schottky Diode with the interface reduced compared to the diode without the interface in terms of the interface states due to the presence of the interface layer used.
\end{abstract}

Keywords: The effect of the interface layer, electric characteristic, terbium, cerium magnesium aluminate

\section{GíRİș}

Nadir Toprak Elementleri (NTE) periyodik tabloda 15 kimyasal elementten özellikle lantanidlerden oluşan bir gruptur. Fakat lantanitlere benzer bir fizyokimyaya sahip olan Skandiyum (Sc) ve İtriyum (Y) da genellikle aynı mineral topluluklarında bulunur ve bunlar da NTE olarak isimlendirilirler. NTE'ler cep telefonu, televizyon, rüzgâr enerji santralleri ve elektrikli araba gibi çeşitli uygulamalarda önemli bir mineral konumundadır (Lederer ve ark., 2017). Bunlar ayrica lazerler, süperiletken miknatıslar ve hibrit otomobillerin pilleri için kritik öneme sahiptir (Mancheri, 2015). Aslında isimlerinin aksine NTE'ler doğada çok nadir bulunmazlar. Örneğin; Seryum (Ce), Bakıra $(\mathrm{Cu})$ benzer bir bolluğa sahiptir ve bolluk bakımından kurşundan $(\mathrm{Pb})$ yaklaşık dört kat daha fazladır 
(Massari ve Ruberti, 2013). Benzer şekilde Lutesyum da ( $\mathrm{Lu})$ Altından $(\mathrm{Au})$ yaklaşık $200 \mathrm{~kat}$ daha boldur (Naumov, 2008). Bu şekilde bol bulunmalarına rağmen asıl sorun bunların mutlak konsantrasyonları değil, göreli konsantrasyonlarıdır. Aslında, bu elementler çok benzer özelliklere sahip olmalarından dolayı basit ekstraksiyon ve ayırma yöntemleri bulmak ve bunları ayrıştırmak çok zordur (Massari ve Ruberti, 2013). NTE hem stratejik değerlerinden hem de ileri teknoloji uygulamalarında kullanımı bakımından çok önemlidir (Binnemans ve Jones, 2015; Liu ve ark., 2019; Nakamura ve Sato, 2011). 2009 y1lında Çin, tüm NTE'lerin \%90 üzerinde üretimine sahipti ("URL-1," 2020). 2011 y1lına gelindiğinde ise bu oran \%90 civarına geriledi (Liang ve Wang, 2014).

Genel olarak NTE'ler atom ve kütle numaralarına göre Hafif Nadir Toprak Elementleri (HNTE), Orta Nadir Toprak Elementleri (ONTE) ve Ağır Nadir Toprak Elementleri (ANTE) olmak üzere üç gruba ayrilırlar (Kato ve ark., 2011; Liang ve ark., 2014). Lantan (La) ve Seryum (Ce) gibi elementler HNTE grubunda, Evropiyum (Eu) ve Gadolinyum (Gd) gibi elementler ONTE grubunda, Terbiyum $(\mathrm{Tb})$ ve Lutesyum ( $\mathrm{Lu}$ ) gibi elementler ise ANTE grubundadır. NTE'ler arasında Tb başlıca katı hal aydınlatması için fosforlarda ve manyetostriktif malzemelerin ana bileşeni gibi çok çeşitli alanlarda kullanılmaktadır (Bonificio ve Clarke, 2016; Liu ve ark., 2020). Tb doğada bolluk açısından NTE'ler içerisinde en az bulunanlarındandir (Chen, 2011).

Metal yarilietken arasında oluşturulan bir arayüzey tabakası Schottky Diyotlarda (SD) hem performans hem de elektriksel parametrelerin iyileştirilmesi için ideal bir yöntem olarak kullanılabilir. Organik (Kacus ve ark., 2020), ferroelektrik (Pei ve ark., 2020) gibi malzemeler Schottky Diyotlarda (SD) arayüzey tabakası olarak kullanılmıştır. Fakat NTE katkı1ı arayüzey tabakaları kullanımı literatürde sınırlıdır. $\mathrm{Bu}$ çalışmada, Terbiyum katk1lı Seryum Magnezyum Alüminat (TSMA) arayüzey tabakasını metal ile yariiletken arasına döner kaplama yöntemi ile oluşturarak elde edilen Al/(TSMA)/p-Si SD'nin elektriksel özellikleri hem Termiyonik Emisyon hem de Norde metodu kullanılarak incelenecektir. Ayrıca arayüzey tabakasının (TSMA) Al/p-Si SD'lerin elektriksel özellikleri ve performansı üzerindeki etkisi de incelenecektir.

\section{MATERYAL VE METOT}

Terbiyum katk11 Seryum Magnezyum Alüminat (TSMA) arayüzey tabakasının $\mathrm{Al} / \mathrm{p}-\mathrm{Si}$ SD'lerin elektriksel özellikleri üzerine etkisini incelemek için aynı yarıiletken kristali kullanılarak $\mathrm{Al} / \mathrm{p}-\mathrm{Si} \mathrm{SD}$ ve Al/(TSMA)/p-Si SD fabrikasyonları gerçekleştirildi. Öncelikle Boron katkı1ı p-Si kristali üzerindeki kirliliklerden kurtulmak için ultrasonik banyoda 5'er dakika boyunca aseton, izopropanol ve saf su ile sırasiyla yıkandı. Daha sonra üzerindeki oksit tabakalardan kurtulmak için yariiletken HF çözeltisinde yıkandı ve tekrar saf su ile iyice duruland1. Durulandiktan hemen sonra kuru azot gazı ile kurutuldu ve hemen termal buharlaştırma sistemine alındi. Burada yaklaşı $10^{-6}$ Torr basınçta üzerinden akım geçen molibden flama yardımıyla kristalin arka mat yüzeyine yüksek saflıkta (\%99.999) Alüminyum (Al) buharlaştırıldı. Düşük dirençli ve yüksek kalitede iyi bir omik kontak elde etmek için arka tarafi kaplı p-Si nitrojen ortamında $450{ }^{\circ} C^{\prime}$ de 30 saniye tavlandı. Sistemden alınan kristal, elmas kesici yardımıyla eşit parçalara bölündü.

$1 \mathrm{ml}$ kloroform ve toz haldeki $10 \mathrm{mg}$ TSMA karışımı bir santrifüj yardımıyla iyice karıştırıldı ve eşit parçalara ayrılmış bir kristal parçasının üzerine döner-kaplama (spin-coating) yöntemiyle damlatılarak arayüzey tabakası kaplandı. Kristal parçalarından arayüzey kaplı olmayan ve arayüzey kaplı olan parça tekrar termal buharlaştırma sistemine alındı. Burada kristal parçalarının ön yüzeylerine $10^{-6}$ Torr'da yüksek vakumlu termal buharlaştırma sisteminde bir metal gölge maske aracılığıyla üzerinden akım geçen molibden flama yardımıla yüksek saflıkta (\%99.999) Al buharlaştırıldı ve $1 \mathrm{~mm}$ çapinda ve $150 \mathrm{~nm}$ kalınlığında dairesel doğrultucu kontaklar oluşturuldu. Fabrikasyonu tamamlanan Al/p-Si SD ve $\mathrm{Al} /(\mathrm{TSMA}) / \mathrm{p}-\mathrm{Si} \quad \mathrm{SD}$ elektriksel ölçümleri Keithley 2400 akım kaynağı kullanılarak gerçekleştirildi.

\section{SONUÇLAR VE TARTIŞMA}

Fabrikasyonu gerçekleştirilen arayüzey kaplı Al/(TSMA)/p-Si SD ve arayüzey tabakası olmayan $\mathrm{Al} / \mathrm{p}-\mathrm{Si}$ SD'lerin Akım-Gerilim $(\ln (\mathrm{A})-\mathrm{V})$ grafiği Şekil 1'de gösterilmiştir. Şekil 1'den de görüldüğü gibi, her iki diyotta $\pm 2 \mathrm{~V}$ için iyi bir Doğrultma Oranına $\left(\mathrm{DO}=\mathrm{I}_{(+2 \mathrm{~V})} / \mathrm{I}_{(-2 \mathrm{~V})}\right)$ sahiptir. Ayrıca doğru beslemde her iki diyotta hem arayüzey durumları 
$\left(\mathrm{N}_{\mathrm{ss}}\right)$ hem de seri direnç $\left(\mathrm{R}_{\mathrm{s}}\right)$ etkisinden dolay1 lineerlikten sapmaktadır. Bir diyot üzerine düşen gerilim ve akım arasındaki ilişki Termiyonik Emisyon (TE) teorisine göre aşağıdaki gibi verilir (Rhoderick ve Williams, 1988; Sze, 1981);

$I=I_{0}\left\{e^{\frac{q\left(V-I R_{S}\right)}{n k T}}-1\right\}$

burada $\mathrm{I}_{0}$ doyma akımıdır ve aşağıdaki gibi tanımlanır (Yerişkin ve ark., 2017).

$I_{0}=A A^{*} T^{2}\left\{e^{\frac{-q \emptyset_{B 0}}{k T}}\right\}$

Burada A, A*, T, q ve $\mathrm{k}$ parametreleri literatürde belirtilmiştir (Reddy ve ark., 2014; Sze, 1981). İdealite faktörü (n) ve sıfır beslem engel yüksekliği $\left(\emptyset_{\mathrm{B} 0}\right)$ aşağıdaki gibi tanımlanır (Card ve Rhoderick, 1971; Yerişkin, 2019);

$n=\frac{q}{k T}\left\{\frac{d V}{d(\ln (I))}\right\}$

$\emptyset_{B 0}=\frac{k T}{q} \ln \left(\frac{A A^{*} T^{2}}{I_{0}}\right)$
İdealite faktörü (n) ve doyma akımı $\left(\mathrm{I}_{0}\right)$ doğru beslemdeki $(\mathrm{V}>0) \quad \ln (\mathrm{I})-\mathrm{V}$ eğrisinin lineer k1smı kullanılarak hesaplanmaktadır. Buna göre; $\mathrm{Al} /(\mathrm{TSMA}) / \mathrm{p}-\mathrm{Si} \mathrm{SD}$ ve Al/p-Si SD için hesaplanan $\mathrm{n}, \mathrm{I}_{0}$ ve $\emptyset_{\mathrm{B} 0}$ değerleri sirasiyla $1.815,3.874 \mathrm{nA}$, $0.715 \mathrm{eV}$ ve $2.545,5.208 \mathrm{nA}$ ve $0.727 \mathrm{eV}$ olarak elde edilmiştir ve Tablo 1'de TE Teorisi kısmında verilmiştir. İdeal durumda, Schottky diyot yapıları için idealite faktörü birim değer olan 1'e eşittir. Fakat uygulamada bu durum gerçek durumdan çok farklı olur. Çünkü arayüzey tabakasının kalınlığı $\left(\delta_{\mathrm{i}}\right)$, arayüzey durumları $\left(\mathrm{N}_{\mathrm{ss}}\right)$, metal/yariiletken arayüzdeki engel homojensizliği, tüketim bölgesi kalınlığı $\left(\mathrm{W}_{\mathrm{D}}\right)$, verici atomların katkılama oranı ve arayüzey rekombinasyonundan dolayı idealite faktörü birim değerden daha büyük değer alabilir (Badali ve ark., 2020; Altındal ve ark., 2020; Bilkan ve ark., 2019). Ayrica, Al/(TSMA)/p-Si SD'nin doyma akımı Al/p-Si SD doyma akımı ile karşılaștırıldığında daha büyüktür. Yarıiletken alttaşta çok sayıda doğal kusur olabilir. Bu kusurlar arayüzey tabakasının da etkisiyle akıma katılabildiklerinden dolayı doyma akımı artar (Reddy ve ark., 2017). Doyma akımın artması diyotun Şönt Direncinin $\left(\mathrm{R}_{\mathrm{sh}}\right)$ azalmasına sebep olur ve dolayısıyla yapının doğrultma oranı azalır.

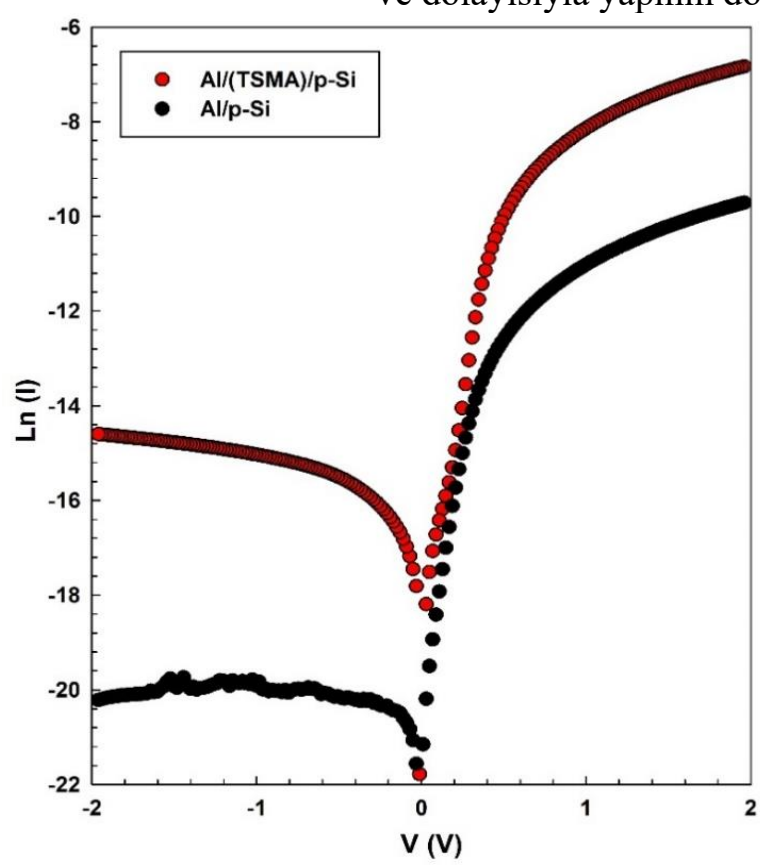

Şekil 1. Al/p-Si ve Al/(TSMA)/p-Si SD'lerin Ln(I)-V grafiği

Tablo 1. Al/p-Si ve Al/(TSMA)/p-Si için farklı yöntemler kullanılarak elde dilen bazı elektriksel parametreler 


\begin{tabular}{|c|c|c|c|c|c|c|c|}
\hline \multirow[b]{2}{*}{ Diyot } & \multicolumn{3}{|c|}{ TE Teorisi } & \multicolumn{2}{|c|}{ Ohm Kanunu } & \multicolumn{2}{|c|}{ Norde Fonksiyonu } \\
\hline & $\mathbf{n}$ & $\begin{array}{c}\mathbf{I}_{\mathbf{0}} \\
(\mathbf{n A})\end{array}$ & $\begin{array}{l}\emptyset_{B 0} \\
(\mathrm{eV})\end{array}$ & $\begin{array}{c}\mathbf{R}_{\mathrm{s}} \\
(\mathbf{k} \boldsymbol{\Omega})\end{array}$ & $\begin{array}{l}\mathbf{R}_{\text {sh }} \\
(\Omega)\end{array}$ & $\begin{array}{l}\emptyset_{B 0} \\
(\mathrm{eV})\end{array}$ & $\begin{array}{c}\mathbf{R}_{\mathrm{s}} \\
(\mathbf{k} \boldsymbol{\Omega})\end{array}$ \\
\hline $\mathbf{A l} / \mathbf{p}-\mathbf{S i}$ & 2.545 & 5.208 & 0.727 & 32.13 & $1.279 \times 10^{9}$ & 0.777 & 51.66 \\
\hline Al/(TSMA)/p-Si & 1.815 & 3.874 & 0.715 & 1.797 & $4.318 \times 10^{6}$ & 0.524 & 0.19 \\
\hline
\end{tabular}

Seri direnç $\left(\mathrm{R}_{\mathrm{s}}\right)$ ve Şönt Direnci $\left(\mathrm{R}_{\text {sh }}\right)$ bir SD'nin kalitesini belirler. $\mathrm{R}_{\mathrm{s}}$ değeri ideal bir diyotta sıfira yakın olması istenirken $R_{s h}$ değerinin maksimum değer alması istenir. Burada $R_{s}$ ve $R_{s h}$ sirasiyla doğru beslem $(\mathrm{V}>0)$ ve ters beslemde $(\mathrm{V}<0)$ yeterli derecede yüksek gerilimdeki yapı direnç $\left(R_{i}\right)$ değerine karşlık gelir. $R_{s}$ kristalin arka yüzeyinde oluşan omik kontak, kristal ile omik kontak arasında büyütme sırasında ya da öncesinde oluşabilecek toz, kir gibi etkenler, metal ile yarıiletken arasında doğal ya da katkılanmış bir arayüzey tabakasının olması ve yarıiletkenin yığın direncinden kaynaklı ortaya çıkar (Nicollian ve Brews, 1982). $\quad \mathrm{R}_{\mathrm{sh}}$ arayüzey boyunca kaçak akım yollarından ve eklem bölgesindeki bazı kusurlardan kaynaklanabilir (Nicollian ve Brews, 1982). Al/p-Si ve Al/(TSMA)/p-Si SD'ler için Ohm Kanunu (Sze, 1981) kullanılarak hesaplanan $R_{i}$ değeri Şekil 2'de verilmiştir. Şekil 2'den de görüldüğü gibi her iki diyotun $R_{i}$ değeri yeterince yüksek gerilim ters beslemde ve yeterince yüksek gerilim doğru beslemde sabit bir değer almaktadır. Bundan dolayı $\mathrm{Al} / \mathrm{p}-\mathrm{Si}$ ve $\mathrm{Al} /(\mathrm{TSMA}) / \mathrm{p}-\mathrm{Si} \mathrm{SD}$ için $\mathrm{R}_{\mathrm{s}}$ ve $\mathrm{R}_{\text {sh }}$ değerleri Ohm Kanunu kullanılarak hesaplanmıștır ve Çizelge 1'de verilmiştir. Bu değerlerden de görüldüğg̈ gibi $\mathrm{Al} /(\mathrm{TSMA}) / \mathrm{p}-\mathrm{Si} \mathrm{SD}$ seri direnci $\mathrm{Al} / \mathrm{p}-\mathrm{Si} \quad \mathrm{SD}$ seri direnciyle karşılaştırıldığında kullanılan arayüzey tabakasının etkisinden dolayı yaklaşık 30 kat küçüktür. Her iki diyotun da seri dirençlerinin yüksek olmasının temel nedeni yariletken kristal ile omik kontak arasında büyütme sırasında ya da öncesinde oluşabilecek toz, kir gibi etkenler, metal ile yariiletken arasında doğal (yerli $\mathrm{SiO}_{2}$ tabakası) ya da katkılanmış bir arayüzey tabakasının (TSMA) olması sonucudur (Nicollian ve Brews, 1982).

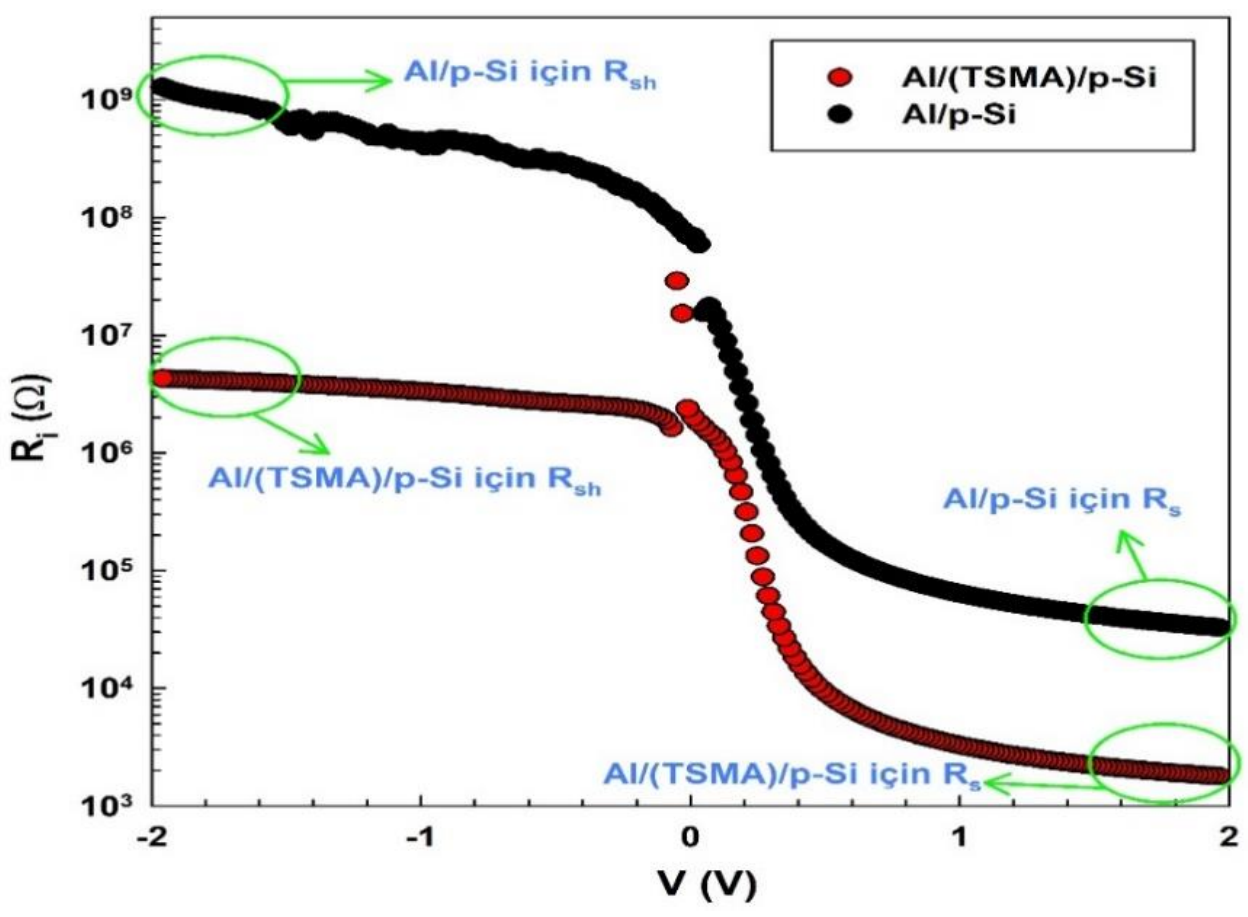

Şekil 2. Al/p-Si ve Al/(TSMA)/p-Si SD’ lerin $\mathrm{R}_{\mathrm{i}}-\mathrm{V}$ grafiği

Bir diyotun $R_{\mathrm{s}}$ değeri ve $\emptyset_{\mathrm{B} 0}$ değeri TE bulunmaktadır. Bunlardan birisi de Norde haricinde başka yöntem ve metotlarla da Fonksiyonudur (Bohlin, 1986; Norde, 1979). Norde 
Fonksiyonuna göre $R_{S}$ ve $\emptyset_{B 0}$ değerleri aşağıdaki eşitlikler kullanılarak bulunabilmektedir (Norde, 1979; Sevgili ve ark., 2020; Tecimer ve ark., 2018).

$F(V)=\frac{V}{\gamma}-\frac{k T}{q} \ln \left\{\frac{I}{A A^{*} T^{2}}\right\}$

$\emptyset_{B}=F(V)_{\min }+\frac{V_{\min }}{\gamma}-\frac{k T}{q}$

$R_{s}=\frac{k T(\gamma-n)}{q I_{\min }}$

Burada $\gamma$ TE teorisinde bulunan idealite faktöründen büyük en küçük tamsayı, $V_{\text {min }} \mathrm{F}(\mathrm{V})-\mathrm{V}$ grafiğinde minimum noktaya karşılık gelen gerilim değeri, $I_{\min }$ ise $\mathrm{V}_{\text {min }}$, e karşılık gelen minimum akım değeridir. Şekil 3, hem Al/p-Si hem de Al/(TSMA)/p-Si SD için $F(V)-V$ grafiğini göstermektedir. Şekil 3 'ten de görüldüğü gibi her iki diyot için de $F(V)$ minimum noktalar1 orta doğru beslem bölgesine $(0<\mathrm{V}<0.5)$ karşıllık gelmektedir. Eşitlik (2.b) ve (2.c) kullanılarak hesaplanan $\emptyset_{\mathrm{B} 0}$ ve $\mathrm{R}_{\mathrm{s}}$ değerleri Çizelge 1'de Norde Fonksiyonu sütununda verilmistir. Hem Norde fonksiyonu hem de TE teorisinden elde edilen değerlerin birbirinden çok az farklı olduğu görülmektedir. Bunun temel nedeni iki yönteminde farklı gerilimlere karșıllk gelen bölgeleri kullanmasından kaynaklanmaktadır (Norde, 1979; Sevgili ve ark., 2020).

Bir diyotun doğru beslemdeki akım iletim mekanizmasını (AİM) incelemek için doğru beslemdeki $\ln \left(\mathrm{I}_{\mathrm{F}}\right)-\ln \left(\mathrm{V}_{\mathrm{F}}\right)$ grafiği çizilmelidir. Bundan dolay1 Al/p-Si ve Al/(TSMA)/p-Si SD'ler için çizilen $\ln \left(\mathrm{I}_{\mathrm{F}}\right)-\ln \left(\mathrm{V}_{\mathrm{F}}\right)$ grafiği Şekil 4'te verilmiştir. Şekil 4'ten de görüldüğü gibi hem $\mathrm{Al} / \mathrm{p}$ Si hem de Al/(TSMA)/p-Si SD için üç lineer bölge oluşmaktadır ve bunlar sırasıyla Bölge 1, Bölge 2 ve Bölge 3 olarak isimlendirilmişlerdir. Böyle lineerliğe sahip bir grafikte uygulanan gerilim ve akım arasında $I \sim V_{m}$ ilişkisi vardır (Eroğlu ve ark., 2020). Burada $m$ değeri $\ln \left(\mathrm{I}_{\mathrm{F}}\right)-\ln \left(\mathrm{V}_{\mathrm{F}}\right)$ grafiğinin eğimidir ve her bir diyotun her bir lineer bölgesi için ayrı ayrı hesaplanır.

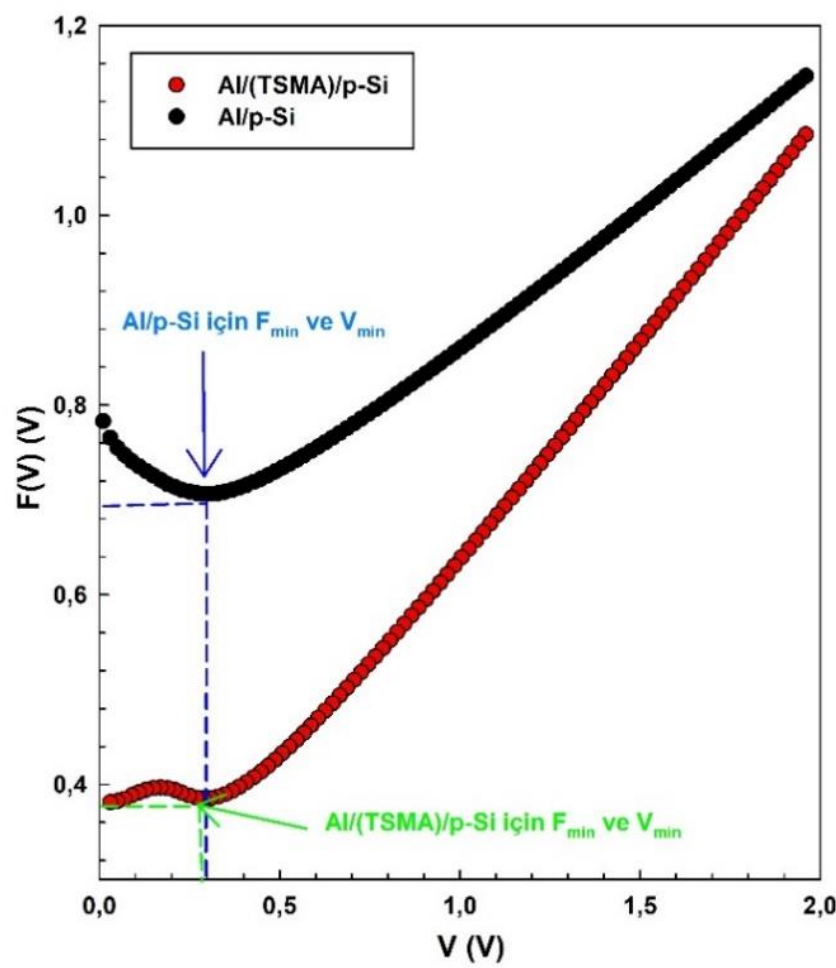

Şekil 3. $\mathrm{Al} / \mathrm{p}-\mathrm{Si}$ ve Al/(TSMA)/p-Si SD’ lerin $\mathrm{F}(\mathrm{V})-\mathrm{V}$ grafiği 


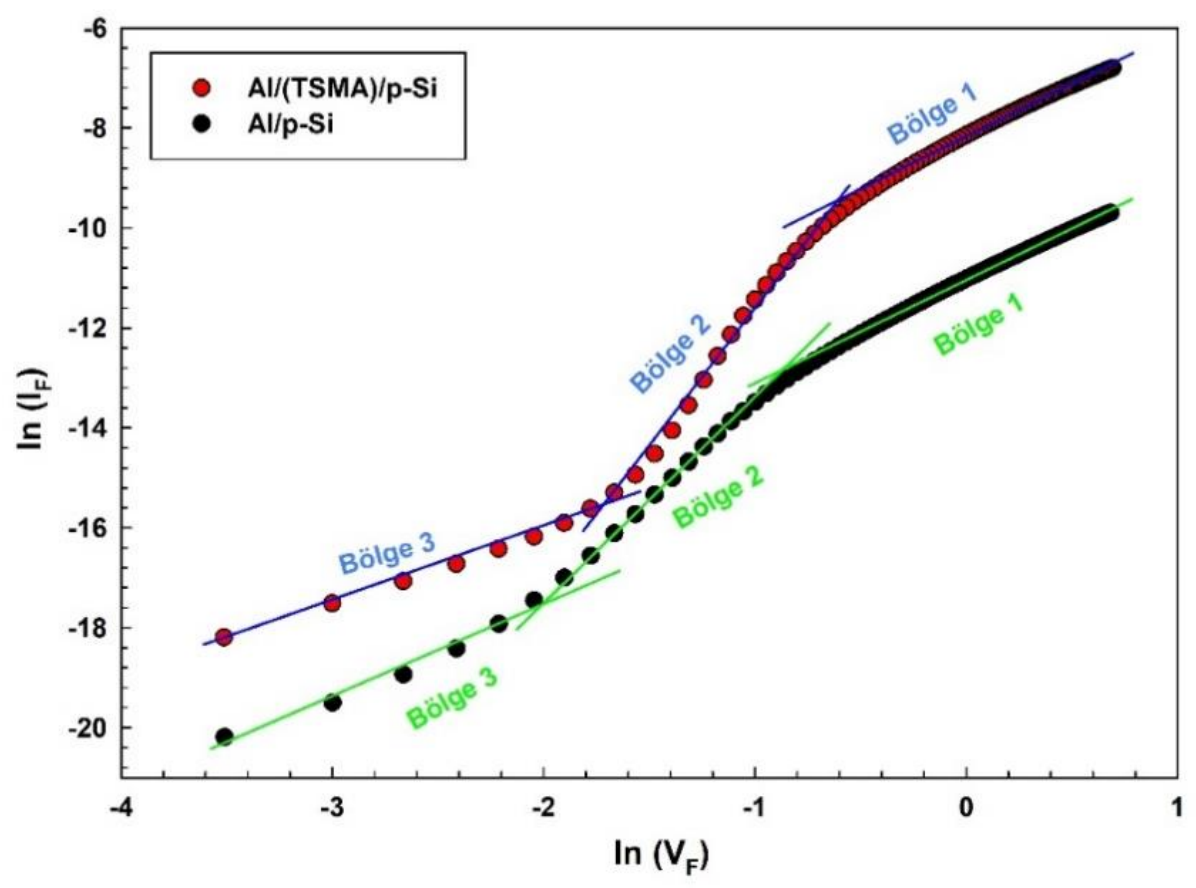

Şekil 4. Al/p-Si ve Al/(TSMA)/p-Si SD' lerin ln $\left(\mathrm{I}_{\mathrm{F}}\right)-\ln \left(\mathrm{V}_{\mathrm{F}}\right)$ grafiği

$\mathrm{m}=\sim 2 \quad$ olduğunda alan-şarjl1-sınırl1-akım (ASSA) davranışı sergilemektedir yani uygulanan akım arttıça elektrottan filme enjekte olan elektronların artmasını göstermektedir. Enjekte edilen elektron sayısındaki artış, tuzakları doldurmaya ve uzay yüklerinin ortaya çıkmasına neden olur. $m>2$ olduğu zaman ise güçlü elektron enjeksiyonu nedeniyle, elektronlar tuzaklardan kaçar ve tuzak-şarjlı-sınırlı-akım (TSSA) alan-şarjlısinırl1-akımına katkıda bulunur (Bengi ve ark., 2010; Wagle ve Shirodkar, 2000; Tataroğlu ve ark., 2020a). Al/p-Si SD için Bölge 1, Bölge 2 ve Bölge 3 lineer kısımlarında hesaplanan $\mathrm{m}$ değerleri sırasıyla 2.28, 3.60 ve 1.21 olarak, Al/(TSMA)/p-Si SD için ise Bölge 1, Bölge 2 ve Bölge 3 lineer kısımlarından hesaplanan $m$ değerleri sirasiyla $2.34,6.38$ ve 1.51 olarak bulunmuştur. Bu durumlar gösteriyor ki her iki diyotta Bölge 1'de ASSA baskın durumda iken, Bölge 2'de TSSA ve Bölge 3'te ise omik davranış baskın durumdadır.

Arayüzey durumları $\left(\mathrm{N}_{\mathrm{ss}}\right)$ bir diyotun elektrik ve dielektrik özelliklerini etkiler ve idealden sapmasina neden olur. Yani arayüzey tabakası ve yarıiletken arasında yerleşmiş $\mathrm{N}_{\mathrm{ss}}$ 'lerin varlığ aygıtın akım-gerilim ve kapasitans-gerilim ölçümlerine etki eder. $\mathrm{N}_{\mathrm{ss}}$ enerjiye bağlı değişim grafiği aşağıdaki eşitlikler ve doğru beslem I-V verileri kullanılarak hesaplanabilir (Card ve Rhoderick, 1971; Tataroğlu ve ark., 2020b).

$$
\begin{aligned}
& n(V)=\frac{q}{k T}\left\{\frac{V-I R_{S}}{\ln \left(\frac{I}{I_{0}}\right)}\right\} \\
& \emptyset_{e}=\emptyset_{B 0}+\left(1-\frac{1}{n(V)}\right)\left(V-I R_{S}\right) \\
& E_{S S}-E_{V}=\mathrm{q}\left(\emptyset_{e}-V\right) \\
& N_{S S}(V)=\frac{1}{q}\left\{\frac{\varepsilon_{i}}{\delta_{i}}(n(V)-1)-\frac{\varepsilon_{S}}{W_{D}}\right\}
\end{aligned}
$$

Burada $\emptyset_{\mathrm{e}}$ effektif engel yüksekliği, $\mathrm{E}_{\mathrm{ss}}$ arayüzey durum enerjisi, $E_{v}$ valans band 1 enerjisidir. $W_{D}$ $\left(=\sqrt{\left\{2 \varepsilon_{S} \varepsilon_{0}\left(V_{0}+k T / q\right)\right\} / q N_{A}}\right)$ tüketim bölgesi kalınlığıdır ve her iki diyot için de $1 \mathrm{MHz}$ ' deki ters beslem $\mathrm{C}^{-2}-\mathrm{V}$ grafiğinin eğiminden bulunan voltaj eksenini kestiği nokta $\left(\mathrm{V}_{0}\right)$ ve katk1 atomlarının yoğunluğu $\left(\mathrm{N}_{\mathrm{A}}\right)$ kullanılarak hesaplanmaktadır. Hem $\mathrm{Al} / \mathrm{p}-\mathrm{Si}$ hem de Al/(TSMA)/p-Si SD hesaplanan $\mathrm{W}_{\mathrm{D}}$ değeri sirasıyla $2.14 \times 10^{-4}, 5.11 \times 10^{-5} \mathrm{~cm}$ olarak bulunmuştur. 


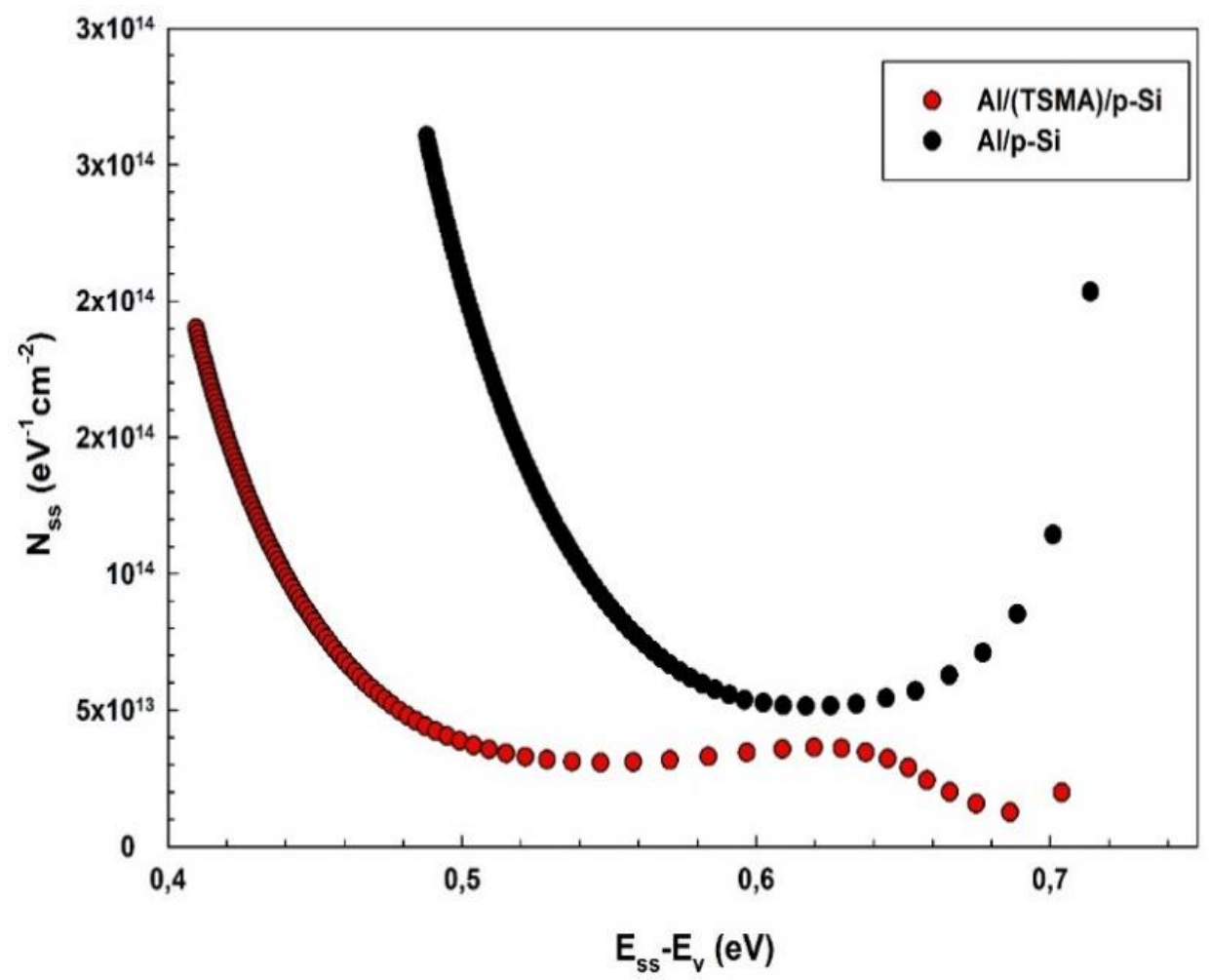

Şekil 5. Al/p-Si ve Al/(TSMA)/p-Si SD’ lerin $\mathrm{N}_{\mathrm{ss}}-\left(\mathrm{E}_{\mathrm{ss}}-\mathrm{E}_{\mathrm{v}}\right)$ grafiği

Ayrıca, her iki diyot için de arayüzey kalınlıkları 1 MHz'deki yalitkan tabaka kapasitansından $\left(\mathrm{C}_{\mathrm{i}}=\varepsilon_{\mathrm{i}} \varepsilon_{0} \mathrm{~A} / \delta_{\mathrm{i}}\right) \quad$ hesaplanabilir. Buna göre Al/(TSMA)/p-Si SD için $\delta_{i}$ değeri yaklaşık olarak $19.6 \mathrm{~nm}$ ve yerli yalıtkan tabakaya $\left(\mathrm{SiO}_{2}\right)$ sahip olan $\mathrm{Al} / \mathrm{p}-\mathrm{Si} \mathrm{SD}$ için $\delta_{\mathrm{i}}$ değeri yaklaşık olarak $3.5 \mathrm{~nm}$ bulunmuştur. $\mathrm{Al} / \mathrm{p}-\mathrm{Si}$ ve $\mathrm{Al} /(\mathrm{TSMA}) / \mathrm{p}-\mathrm{Si} \mathrm{SD}$ için elde edilen $\mathrm{N}_{\mathrm{ss}}$ enerji dağılım grafiği Şekil 5'te verilmiştir. Şekilden de görüldüğü gibi, arayüzey tabakasının etkisinden dolayı sarkan bağlar pasifleşmiştir ve verilen enerji bölgesinde $\mathrm{Al} /(\mathrm{TSMA}) / \mathrm{p}-\mathrm{Si} \quad \mathrm{SD}$ için $\mathrm{N}_{\mathrm{ss}}$ değerleri daha düşüktür. Bu arayüzey tabakanın varlığı, taşıyıcıların metal-yarı iletken bağlantısından içeri girmesini engellemekle kalmaz, aynı zamanda yarı iletken yüzeydeki aktif sarkan bağları da etkisiz hale getirir. (Reddy, 2014). Bu sonuç, (TSMA) arayüzey tabakasının varlığının, Al/(TSMA)/p-Si SD' nin $\mathrm{N}_{\mathrm{ss}}$ değerinin $\mathrm{Al} / \mathrm{p}$-Si'e göre azalmasına neden olduğunu ve performansını iyileştirdiğinin bir başka göstergesidir. Arayüzey durumlarının yüksek olmasının temel nedenleri arasında özellikle metal ile yariiletken arasında oluşabilecek ince bir yerli oksit tabaka, arayüzey tabakası oluştururken oluşabilecek kirlilikler, tüketim bölgesi kalınlığı ve arayüzey tabakasının yüksek dielektrik değere sahip olmas1 gösterilebilir (Yakuphanoğlu, 2008; Taşçıŏlu ve ark., 2012).

Her iki diyot için de elde edilen deneysel değerlerden de anlaşıllyor ki Al/(TSMA)/p-Si SD için hesaplanan seri direnç $\left(R_{s}\right)$, idealite faktörü $(n)$ ve arayüzey durumları $\left(\mathrm{N}_{\mathrm{ss}}\right)$ değerleri $\mathrm{Al} / \mathrm{p}-\mathrm{Si} \mathrm{SD}$ için hesaplanan değerlerle kıyaslandığında arayüzey tabakası (TSMA) bu parametreleri iyileştirmiştir.

\section{SONUÇ}

Terbiyum katkılı Seryum Magnezyum Alüminat (TSMA) arayüzey tabakasının, arayüzeye sahip Al/(TSMA)/p-Si SD ve arayüzeye sahip olmayan Al/p-Si SD hazırland ve bunların elektriksel ölçümleri gerçekleştirildi. I-V verileri kullanılarak TE teorisinden $\mathrm{n}, \mathrm{R}_{\mathrm{s}}, \mathrm{I}_{0}$ ve $\emptyset_{\mathrm{B} 0}$ değerleri, Norde foksitonundan ise $R_{S}$ ve $\emptyset_{B}$ değerleri hesaplandı. Elde edilen değerlerin arasında çok küçük farklar olduğu ve bu farkların kullanılan metodun doğasına yani çalışma gerilim bölgelerinin 
farklılıklarından kaynaklanmasından dolayı oluştuğu belirtildi. Al/(TSMA)/p-Si SD için elde edilen $\mathrm{N}_{\mathrm{ss}}$ değeri $\mathrm{Al} / \mathrm{p}-\mathrm{Si} \mathrm{SD}$ için elde edilen $\mathrm{N}_{\mathrm{ss}}$ değerinden düşük olduğu görüldü. Deneysel olarak elde edilen veriler 1 șı ğında anlaşıllyor ki, Terbiyum katkı1ı Seryum Magnezyum Alüminat idealite faktörünün değerini ideal durum olan 1'e yaklaştırmış, seri direncin ve arayüzey durumlarının iyileştirmesine katkı sağlamıştır. Bu çalışmanın sonucunda açıkça görülüyor ki NTE'lerden birisi ile katkılanmış olan Terbiyum katkılı Seryum Magnezyum Alüminat (TSMA) arayüzey tabakası içeren aygıtın elektriksel performansında bazı iyileştirmeler gerçekleşmiştir.

\section{ÇIKAR ÇATIŞMASI BEYANI}

Yazar, bu makale ile ilgili herhangi bir çıkar çatışması bildirmedi.

\section{ARAŞTIRMA VE YAYIN ETİĞİ BEYANI}

Yazar, bu çalışmanın araştırma ve yayın etiğine uygun olduğunu beyan eder.

\section{KAYNAKLAR}

Altindal, Ş., Farazin, J., Pirgholi-Givi, G., Maril, E., Azizian-Kalandaragh, Y., 2020. The effects of $\left(\mathrm{Bi}_{2} \mathrm{Te}_{3}-\mathrm{Bi}_{2} \mathrm{O}_{3}-\mathrm{TeO}_{2}-\mathrm{PVP}\right)$ interfacial film on the dielectric and electrical features of $\mathrm{Al} / \mathrm{p}-\mathrm{Si}$ (MS) Schottky barrier diodes (SBDs). Physica B: Condensed Matter, 582:411958.

Badali, Y., Azizian-Kalandaragh, Y., Uslu, İ., Altindal, Ş., 2020. Investigation of the effect of different $\mathrm{Bi}_{2} \mathrm{O}_{3}-\mathrm{x}$ : PVA $(\mathrm{x}=\mathrm{Sm}, \mathrm{Sn}, \mathrm{Mo})$ thin insulator interface-layer materials on diode parameters. Journal of Materials Science: Materials in Electronics, 31:8033-8042.

Bengi, A., Aydemir, U., Altindal, Ş., Özen, Y., Özçelik, S., 2010. A comparative study on the electrical characteristics of $\mathrm{Au} / \mathrm{n}-\mathrm{Si}$ structures with anatase and rutile phase $\mathrm{TiO}_{2}$ interfacial insulator layer. Journal of Alloys and Compounds, 505:628-633.

Bilkan, Ç., Azizian-Kalandaragh, Y., Sevgili, Ö., Altındal, Ş., 2019. Investigation of the efficiencies of the $\left(\mathrm{SnO}_{2}-\mathrm{PVA}\right)$ interlayer in $\mathrm{Au} / \mathrm{n}-\mathrm{Si}$ (MS) SDs on electrical characteristics at room temperature by comparison. Journal of Materials Science: Materials in Electronics, 30:20479-20488.

Binnemans, K., Jones, P. T., 2015. Rare Earths and the Balance Problem. Journal of Sustainable Metallurgy, 1:29-38.

Bohlin, K. E., 1986. Generalized Norde plot including determination of the ideality factor. Journal of Applied Physics, 60:1223-1224.

Bonificio, W. D., Clarke, D. R., 2016. Rare-Earth Separation Using Bacteria. Environmental Science \& Technology Letters, 3:180-184.

Card, H. C., Rhoderick, E. H., 1971. Studies of tunnel MOS diodes I. Interface effects in silicon Schottky diodes. Journal of Physics D: Applied Physics, 4:1589-1601.

Chen, Z., 2011. Global rare earth resources and scenarios of future rare earth industry. Journal of Rare Earths, 29:1-6.

Eroğlu, A., Demirezen, S., Azizian-Kalandaragh, Y., Altındal, S., 2020. A comparative study on the electrical properties and conduction mechanisms of $\mathrm{Au} / \mathrm{n}-\mathrm{Si}$ Schottky diodes with/without an organic interlayer. Journal of Materials Science: Materials in Electronics, 31:14466-14477.

Kacus, H., Yilmaz, M., Kocyigit, A., Incekara, U., Aydogan, S., 2020. Optoelectronic properties of $\mathrm{Co} /$ pentacene/Si MIS heterojunction photodiode. Physica B: Condensed Matter, 597:412408.

Kato, Y., Fujinaga, K., Nakamura, K., Takaya, Y., Kitamura, K., Ohta, J., Toda, R., Nakashima, T., Iwamori, H., 2011. Deep-sea mud in the Pacific Ocean as a potential resource for rare-earth elements. Nature Geoscience, 4:535-539.

Lederer, F. L., Curtis, S. B., Bachmann, S., Dunbar, W. S., MacGillivray, R. T. A., 2017. Identification of lanthanum-specific peptides for future recycling of rare earth elements from compact fluorescent lamps. Biotechnology and Bioengineering, 114:1016-1024.

Liang, T., Li, K., Wang, L., 2014. State of rare earth elements in different environmental components in mining areas of China. Environmental Monitoring and Assessment, 186:1499-1513.

Liu, H., Zhang, Y., Luan, Y., Yu, H., Li, D., 2020. Research Progress in Preparation and Purification of Rare Earth Metals. Metals, 10:1-13. 
Liu, Y.-F., Zhang, S.-G., Liu, B., Shen, H.-L., 2019. An alkaline fusion mechanism for aluminate rare earth phosphor: cation-oxoanion synergies theory. Rare Metals, 38:299-305.

Mancheri, N. A., 2015. World trade in rare earths, Chinese export restrictions, and implications. Resources Policy, 46:262-271.

Massari, S., Ruberti, M., 2013. Rare earth elements as critical raw materials: Focus on international markets and future strategies. Resources Policy, 38:36-43.

Nakamura, E., Sato, K., 2011. Managing the scarcity of chemical elements. Nature Materials, 10:158-161.

Naumov, A. V., 2008. Review of the world market of rare-earth metals. Russian Journal of Non-Ferrous Metals, 49:14-22.

Nicollian, E. H., Brews, J. R., 1982. Metal Oxide Semiconductor (MOS) Physics and Technology. New York.

Norde, H., 1979. A modified forward I-V plot for Schottky diodes with high series resistance. Journal of Applied Physics, 50:5052-5053.

Pei, W., Chen, J., You, D., Zhang, Q., Li, M., Lu, Y., Fu, Z., He, Y., 2020. Enhanced photovoltaic effect in $\mathrm{Ca}$ and $\mathrm{Mn}$ co-doped $\mathrm{BiFeO}_{3}$ epitaxial thin films. Applied Surface Science, 530:147194.

Reddy, M.S.P., Sreenu, K., Reddy, V.R., Park, C., 2017. Modified electrical properties and transport mechanism of Ti/p-InP Schottky structure with a polyvinylpyrrolidone (PVP) polymer interlayer. Journal of Materials Science: Materials in Electronics, 28:4847-4855.

Rajagopal Reddy, V., Manjunath, V., Janardhanam, V., Kil, Y. H., Choi, C. J., 2014. Electrical properties and current transport mechanisms of the Au/n-GaN Schottky structure with solution- processed high-k $\mathrm{BaTiO}_{3}$ interlayer. Journal of Electronic Materials, 43: 3499-3507.

Reddy, V. R., 2014. Electrical properties of Au/polyvinylidene fluoride/n-InP Schottky diode with polymer interlayer. Thin Solid Films, 556:300306.

Rhoderick, R. H., Williams, E. H., 1988. MetalSemiconductor Contacts (2nd ed.). London: Oxford University Press.

Sevgili, Ö., Yıldırım, M., Azizian-Kalandaragh, Y.,
Altındal, Ş., 2020. A comparison study regarding $\mathrm{Al} / \mathrm{p}-\mathrm{Si}$ and $\mathrm{Al} /($ carbon nanofiber-PVP)/p-Si diodes: current/impedance-voltage (I/Z-V) characteristics. Applied Physics A, 126:634.

Sze, S. M., 1981. Physics of Semiconductor Devices (2nd ed.). New York: Willey.

Taşçıŏlu, İ., Soylu, M., Altındal, Ş., Al-Ghamdi, A.A., Yakuphanoğlu, F., 2012. Effects of interface states and series resistance on electrical properties of $\mathrm{Al} /$ nanostructure $\mathrm{CdO} / \mathrm{p}-\mathrm{GaAs}$ diode. Journal of Alloys and Compounds, 541:462-467.

Tataroğlu, A., Büyükbaş Ulusan, A., Altındal, Ş., Azizian-Kalandaragh, Y., 2020a. A Compare Study on Electrical Properties of MS Diodes with and Without $\mathrm{CoFe}_{2} \mathrm{O}_{4}$-PVP Interlayer. Journal of Inorganic and Organometallic Polymers and Materials, doi.org/10.1007/s10904-020-01798-X

Tataroğlu, A., Altındal, Ş., Azizian-Kalandaragh, Y., 2020b. Comparison of electrical properties of MS and MPS type diode in respect of $\left(\mathrm{In}_{2} \mathrm{O}_{3}\right.$-PVP) interlayer. Physica B: Condensed Matter, 576:411733.

Tecimer, H.U., Alper, M.A., Tecimer, H., Tan S.O., Altındal, Ş., 2018. Integration of Zn-doped organic polymer nanocomposites between metal semiconductor structure to reveal the electrical qualifications of the diodes, Polymer Bulletin, 75:4257-4271.

URL-1.2020.

https://www.gao.gov/new.items/d10617r.pdf/ Amerika Birleşik Devletleri Hükümeti Sorumluluk Ofisi, Savunma Tedarik Zincirinde Nadir Bulunan Toprak Malzemeler. 10 Aralık 2020.

Wagle, S., Shirodkar, V., 2000. Space-charge-limited conduction in thin film $\mathrm{Al} / \mathrm{Sb}_{2} \mathrm{~Pb}_{1} \mathrm{Se}_{7} / \mathrm{Al}$ devices. Brazilian Journal of Physics, 30: 380-385.

Yakuphanoğlu, F., 2008. Analysis of interface states of metal-insulator-semiconductor photodiode with ntype silicon by conductance technique. Sensors and Actuators A: Physical, 147: 104-109.

Yerişkin, S.A., 2019. The investigation of effects of $\left(\mathrm{Fe}_{2} \mathrm{O}_{4}\right.$-PVP) organic-layer, surface states, and series resistance on the electrical characteristics and the sources of them. Journal of Materials Science: Materials in Electronics, 30:17032-17039. 
Yerişkin, S.A., Balbaşı, M., Orak, İ., 2017. The effects of (graphene doped-PVA) interlayer on the determinative electrical parameters of the $\mathrm{Au} / \mathrm{n}-\mathrm{Si}$ (MS) structures at room temperature. Journal of Materials Science: Materials in Electronics, 28:14040-14048. 